\title{
The angiogenetic pathway in malignant pleural effusions: Pathogenetic and therapeutic implications (Review)
}

\author{
FOTEINI ECONOMIDOU, GEORGE MARGARITOPOULOS, \\ KATERINA M. ANTONIOU and NIKOLAOS M. SIAFAKAS \\ Department of Thoracic Medicine, Medical School, University of Crete, Heraklion, Greece
}

Received August 7, 2009; Accepted October 6, 2009

DOI: 10.3892/etm_00000001

\begin{abstract}
Increased permeability of the pleural microvasculature is generally attributed to the substances that are released in inflammatory and malignant pleural effusions, although the exact pathogenetic mechanisms of malignant pleural effusions are unclear. Current therapies used to prevent the re-accumulation of pleural fluid and relieve symptoms are of variable efficacy and may cause serious adverse effects. Understanding the mechanisms of fluid accumulation would hopefully permit the development of more specific, effective and safer treatment modalities. Angiogenesis, pleural vascular increased permeability and inflammation are considered central to the pathogenesis of malignant pleural effusions. Vascular endothelial growth factor (VEGF) is a member of the VEGF/platelet-derived factor gene family and consists of at least six isoforms. Since it was shown that VEGF contributes to the formation of malignant pleural effusions, there have been some attempts to implicate, therapeutically, this finding using different molecules (ZD6474, PTK 787 and bevacizumab). However, the role of the biological axis of VEGF and angiopoietins needs further investigation in both the pathogenesis and the treatment of malignant pleural effusion. In both non-small-cell lung carcinoma and breast cancer, it has been shown that the ligand for CXCR4, CXCL12 or SDF-1 $\alpha$, exhibited peak levels of expression in organs that were the preferred destination for their respective metastases. Recent findings imply that new therapeutic strategies aimed at blocking the SDF-1-CXCR4 axis may have significant applications for patients by modulating the trafficking of hemato/lymphopoietic cells and inhibiting the metastatic behavior of tumor cells as well. The purpose of this report is to review novel pathogenetic and therapeutic implications
\end{abstract}

Correspondence to: Dr Katerina M. Antoniou, Department of Thoracic Medicine, Medical School, University of Crete, Heraklion, Greece

E-mail: katerinaantoniou@yahoo.gr

Key words: angiogenesis, pleural effusions regarding the angiogenetic pathways in malignant pleural effusions.

\author{
Contents \\ 1. Introduction \\ 2. Main angiogenetic factors \\ 3. CXCR4/stromal cell-derived factor-1 pathway \\ 4. Conclusion
}

\section{Introduction}

Malignant pleural effusion is a common condition, observed in patients with lung cancer and is associated with poor survival and quality of life (1-3). At least $25 \%$ of patients with lung cancer develop pleural effusion during the course of their disease.

Pleural effusion formation is multifunctional. At least, pleural effusion formation is associated with i) impaired drainage of the pleural space due to obstruction of vessels and lymphatics of the lung and pleura, ii) increased pleural formation and iii) inflammation and associated vascular increased permeability, resulting in plasma leakage; these are fundamental to the development of exudative, protein-rich pleural effusions (4-7). Increased permeability of the pleural microvasculature is generally attributed to factors that are released in inflammatory and malignant pleural diseases (7), although the exact pathogenetic mechanisms of malignant pleural effusion are unclear.

Current therapies used to prevent the re-acumulation of pleural fluid and relieve symptoms include pleurodesis (chemical-induced pleural fibrosis aiming at eliminating the pleura space), indwelling pleural catheters and chemotherapy. All of these are of variable efficacy and may cause serious adverse effects $(1-3,8)$. Understanding the mechanisms of the disease would hopefully permit the development of more specific, effective and safer treatment modalities.

Angiogenesis, pleural vascular increased permeability and inflammation are considered central to the pathogenesis and possible therapeutic approaches in malignant pleural effusion (3,9-12). The purpose of this report is to review the novel pathogenetic mechanisms regarding the angiogenetic 
pathway in malignant pleural effusions and the possible new therapeutic implications.

\section{Main angiogenetic factors}

Vascular endothelial growth factor. Vascular endothelial growth factor (VEGF) is a member of the VEGF/plateletderived factor gene family and consists of at least six isoforms (VEGF-121, -145, -165, -183, -189 and -206) which are regulated by splicing at the mRNA level. VEGF can bind to two tyrosine kinase receptors, which are VEGFR-1 (flt-1) and VEGFR-2 (FLK-1/KDR) seated on the surface of endothelial cells. Once VEGF binds to these receptors, it induces dimerization, autophosphorylation and signal transduction. Notably, VEGF has potent angiogenic, mitogenic and vascular permeability-enhancing properties (13-18). Studies have shown that VEGF is overexpressed in human tumors (19) and plays an important role in the development of certain types of effusion (17,20-23). In agreement with previous studies (24-27), our group recently showed that VEGF levels are significantly higher in exudates than in transudates. Moreover, we found higher levels of VEGF in malignant than in parapneumonic effusions, and VEGF levels were correlated with markers of increased vascular permeability and pleural inflammation, such as LDH and protein ratios (28) in accord with recent studies $(27,29)$.

Since it was shown that VEGF contributes to the formation of malignant pleural effusions, there have been some attempts to implicate, therapeutically, this finding. ZD6474 is an orally active inhibitor of VEGFR-2 with some additional activity against epidermal growth factor receptor tyrosine kinase (30-35). Matsumori et al investigated whether this drug controls experimental metastasis and pleural effusions produced by human non-small-cell lung carcinoma (NSCLC). They found that treatment with ZD6474 inhibits activation of VEGFR-2 and reduces tumor vascularization and tumor cell proliferation (36). Shibuya et al combined ZD6474 with radiation therapy using an orthotopic nude mouse model of NSCLC that closely mimics the patterns of tumor growth (37). This combination significantly enhanced the antiangiogenic, antivascular and anti-tumor effects of radiotherapy and was more effective than combined radiotherapy and chemotherapy (37).

PTK 787 is a VEGF receptor tyrosine kinase phosphorylation inhibitor. The efficiency of this agent has been examined in malignant pleural effusion developed in mice (38). It has been noted that oral administration of PTK 787 suppressed pleural effusion formation by inhibiting vascular permeability (38). It has been shown that, given orally, this agent exhibits excellent activity and tolerability, thus it can be used for longterm therapy of malignancies and for other diseases where VEGF mediates angiogenesis and plays an important role in their pathogenesis (39).

Bevacizumab is a humanized anti-VEGF monoclonal neutralizing antibody which blocks the binding of VEGF to its receptor and neutralizes all the isoforms of human VEGF. $\mathrm{Li}$ and co-workers used a patient-like severe combined immunodeficient mouse model by the orthotopic implantation of malignant pleural mesothelioma cells in order to examine the therapeutic efficiency of this agent (40). Administration of bevacizumab managed to suppress pleural effusion formation. Moreover, they showed that the combination of bevacizumab with pemetrexed, a new anticancer drug recently approved for the therapy of malignant pleural mesothelioma, augmented this effect (40).

Malignant mesothelioma cells express a number of receptor tyrosine kinase including VEGF receptor, epidermal growth factor receptor, platelet-derived growth factor receptor and Eph receptors (41-43). The Eph transmembrane tyrosine kinases constitute the largest family of receptor tyrosine kinases. EphA2 receptor is overexpressed during various processes such as tumor growth, angiogenesis and metastasis, and is also overexpressed in aggressive malignances (44-47). A recent in vitro study showed that silencing the EphA2 receptor using small interfering RNA inhibits the growth and migration of malignant mesothelioma cells. Silencing the EphA2 gene can induce apoptosis in malignant mesothelioma cells through caspase-9 activation (41-43). Conversely, when the receptor is overexpressed, this increases the proliferation and migration of malignant mesothelioma cells. Thus, knocking down the oncogenic protein EphA2 may have therapeutic implications in patients with malignant mesothelioma (48). It has also been noted that activation of the EphA2 receptor by its ligand ephrinA1 downregulates total EphA2 expression via phosphorylation and inhibits mesothelioma cell formation (49).

Endostatin. Endostatin, a 20-kDa C-terminal fragment of collagen XVIII, is released by normal cells and tissues. Endostatin specifically inhibits endothelial proliferation and potently inhibits angiogenesis and tumor growth $(50,51)$. It has been recently observed that thoracoscopic talc insufflation induces pleural mesothelial cells to release endostatin (52). It seems that talc insufflation may alter the angiogenic balance in the pleural space upregulating angiostasis (52). However, further studies are needed to clarify these findings in humans.

Hyaluronan. Hyaluronan (HA) is a non-sulfated glycosaminoglycan that is secreted in significant quantities by pleural mesothelial cells and malignant mesothelioma cells (53). Its receptor, CD44, is expressed by malignant cells with a predilection for the pleura. High molecular weight HA is inactive, while low molecular weight HA produced by hydrolysis of the high molecular weight HA is chemotactic for malignant cells and also has angiogenic properties increasing permeability of the mesothelial monolayer. Low molecular weight HA induces malignant mesothelial cell proliferation and haptotaxis via interaction of the CD44 receptor (54).

Angiopoietin-1 and -2. Angiopoietin (Ang)-1 and -2 are important regulators of angiogenesis and exert their actions through binding a common tyrosine kinase receptor (Tie-2) that is mainly expressed on the surface of endothelial cells (55). Ang-1 and -2 act in conjunction with VEGF in promoting angiogenesis and occur under both normal and disease conditions (55).

In vivo $(56,57)$ and in vitro studies (58-60) have demonstrated that Ang-1 has anti-inflammatory and antipermeability properties. It blocks the expression of adhesion molecules on the endothelial cell surface, leukocyte adherence on 
endothelial cells and transmigration into tissues and IL-8 production by endothelial cells. In addition, Ang-1 inhibits vascular permeability induced by VEGF and other inflammatory agents. On the other hand, Ang-2 antagonizes the effect of Ang-1 in endothelial cells, suggesting that Ang-2 promotes vascular permeability (61). In agreement with this, Ang-2 destabilizes the endothelial cell monolayer integrity leading to the detachment of endothelial cells in vitro (62). More evidence supporting a hyperpermeability and pro-inflammatory function of Ang-2 comes from an in vivo study in which Ang-2 was found to induce edema formation and to exert a weak stimulatory effect on leukocyte migration when injected into mouse paw (63).

In malignant diseases, Ang-2 induces the instability of blood vessels and facilitates angiogenesis in the presence of VEGF, and it is one of the poor prognostic factors of NSCLC (64). Moreover, another study revealed that Ang-2 levels but not Ang-1 levels are elevated in exudative pleural effusions, suggesting that Ang-2 along with VEGF participate in pleural inflammation and in the pathogenesis of exudative pleural effusions (27). Tomimoto et al confirmed that a high level of VEGF and Ang-2 coexisted in exudative effusion, especially in bloody effusion, and there was a significant correlation between the levels of VEGF and Ang-2 (65). Our group recently demonstrated that, while VEGF is one of the main mediators in exudative malignant pleural effusions, this effect is not mediated through the angiogenetic pathway of angiopoietin receptor Tie-2 (28). In addition, it has been shown that Ang-2 along with VEGF, but not Ang-1, is increased in pleural inflammation (28). However, the role of the above biological axis of VEGF and angiopoietins needs further investigation.

\section{CXCR4/stromal cell-derived factor-1 pathway}

Recently, attention has been given to one particular member of the chemokine receptor family, CXCR4, because of its key role in HIV infection (66). Stromal cell-derived factor-1 $\alpha$ (SDF-1 $\alpha /$ CXCL12) is a member of the CXC chemokine family which has been found to recruit $\mathrm{CD} 34^{+}$hematopoietic progenitor cell, megakaryocytes, B cells and T cells. SDF-1 $\alpha /$ CXCL12 was expressed on target tissues (67). Although most chemokine receptors bind several chemokines, CXCR4 is a specific chemokine receptor since it only interacts with SDF-1 $\alpha$ (68). The involvement of CXCR4 and SDF-1 $\alpha$ in these processes makes this chemokine-receptor pair of particular interest for tumor metastasis. Many previous studies have demonstrated that the metastatic propensity of tumors from several different types of cancer including lung, breast, ovarian, renal and prostate is related to the expression of the chemokine receptor CXCR4 (67-70). Furthermore, in both NSCLC and breast cancer, it has been shown that the ligand for CXCR4/CXCL12 exhibited peak levels of expression in organs that were the most common sites of their metastases $(69,70)$.

Our unpublished data revealed a significant increase in SDF-1 $\alpha$ expression levels at both the mRNA and protein levels in malignant exudates in comparison to controls (71). We detected a coexpression between post-transcriptional expression protein levels of VEGF and SDF-1 $\alpha$ in malignant pleural fluid. These data suggest that SDF-1 $\alpha$ along with VEGF and Ang-2 expression may be involved in the dissemination of malignant cells into pleural space. Disseminated cancer cells can block the drainage of pleural space and this eventually leads to pleural effusion.

SDF-1 exerts pleiotropic effects which regulate processes essential to tumor metastasis, such as locomotion of malignant cells, their chemoattraction and adhesion. It also plays an important role in tumor vascularization (72). This implies that new therapeutic strategies aimed at blocking the SDF-1CXCR4 axis may have important applications in the treatment of pleural effusions by modulating the trafficking of hemato/ lymphopoietic cells and inhibiting the metastatic behavior of tumor cells as well (72). In our study, we contributed to the understanding of the pathophysiology of CXCL12/CXCR4 in association with the interaction with VEGF-angiopoietins (71).

The SDF-1 $\alpha$ levels in malignant pleural effusions were significantly higher than those in transudate pleural effusions and showed a significant positive correlation with pleural effusion volumes (73). Furthermore, cancer cells in malignant pleural effusions expressed CXCR4, and mesothelial cells of the pleura stained positive for SDF-1 $\alpha$ (73). However, there are no studies to support the aforementioned involvement of CXCL12/CXCR4 in malignant pleural effusions of SCLC. Our findings are in agreement with previous studies $(69,73)$, while we found similar data with different-modern methodologies directly in pleural fluid cells of patients with malignancy. This hypothesis raises the possibility that blockade of CXCR4/SDF-1 interaction may lead to the discovery of novel therapeutic molecules.

\section{Conclusion}

Malignant pleural fluid accumulation is developed mostly as a result of increased production, secondary to mutually dependent biological phenomena including an ongoing angiogenic process and the associated enhanced vascular permeability and pleural inflammation. Many recent studies have demonstrated that angiopoietins/Tie-2 axis blockage impairs new vessel formation in the tumor, attenuates pleural vascular leakage and decreases recruitment of inflammatory cells. In this regard, angiopoietins, along with VEGF, are essential to the regulation of tumor angiogenesis. However, the exact role of individual angiopoietin family members is still unknown. SDF-1 $\alpha /$ CXCL12 is expressed on target tissues, and many studies have demonstrated that the metastatic propensity of tumors of several different types of cancer is related to the expression of the chemokine receptor CXCR4. Understanding the mechanisms of fluid accumulation in malignant disease would hopefully lead to development of more specific, effective and safer treatment modalities to prevent the re-accumulation of pleural fluid and relieve symptoms without serious adverse effects.

\section{References}

1. Lee YC and Light RW: Management of malignant pleural effusions. Respirology 9: 148-156, 2004.

2. Antony VE, Loddenkepmper R, Astoul P, et al: Management of malignant pleural effusions. Am J Resp Crit Care Med 162: 1987-2001, 2000. 
3. West SD, Davies RJ and Lee YC: Pleurodesis for malignant pleural effusions: current controversies and variations in practices. Curr Opin Pulm Med 10: 305-310, 2004.

4. Kinasewitz GT: Transudative effusions. Eur Respir J 10: 714-718, 1997.

5. Light RW: Pleural diseases. Dis Mon 38: 261-331, 1992.

6. Yanagama H, Takeuchi E, Suzuki Y, et al: Vascular endothelial growth factor in malignant pleural effusion associated with lung cancer. Cancer Immunol Immunother 48: 396-400, 1999.

7. Lee YCG and Lane KB: Cytokines in pleural diseases. In: Textbook of Pleural Disease. Light RW and Lee YCG (eds). Arnold, London, pp63-89, 2003.

8. Light RW: Talc for pleurodesis? Chest 122: 1506-1508, 2002.

9. Yano S, Shinohara H, Herbst RS, et al: Production of experimental malignant pleural effusions is dependent on invasion of the pleura and expression of vascular endothelial growth factor/ vascular permeability factor by human lung cancer cells. Am J Pathol 157: 1893-1903, 2000.

10. Stathopoulos GT, Zhu Z, Everhart MB, et al: Nuclear factorkappaB affects tumor progression in a mouse model of malignant pleural effusion. Am J Respir Cell Mol Biol 34: 142-150, 2006.

11. Stathopoulos GT, Kollintza A, Moschos C, et al: Tumor necrosis factor-alpha promotes malignant pleural effusion. Cancer Res 67: 9825-9834, 2007.

12. Stathopoulos GT, Psallidas I, Moustaki A, et al: Tumor-derived monocyte chemoattractant protein-1 promotes malignant pleural effusion. J Natl Cancer Inst 100: 1464-1476, 2008.

13. Antony VB: Immunological mechanisms in pleural disease. Eur Respir J 21: 539-544, 2003.

14. McDonald DM: Angiogenesis and remodeling of airway vasculature in chronic inflammation. Am J Respir Crit Care Med 164: S39-S45, 2001.

15. Hoshino M, Takahashi M and Aoike N: Expression of vascular endothelial growth factor, basic fibroblast growth factor and angiogenin immunoreactivity in asthmatic airways and its relationship to angiogenesis. J Allergy Clin Immunol 107: 295-301, 2001.

16. Hoshino M, Nakamura $Y$ and Hamid QA: Gene expression of vascular endothelial growth factor and its receptors and angiogenesis in bronchial asthma. J Allergy Clin Immunol 107: 1034-1038, 2000.

17. Sack U, Hoffmann M, Zhao XJ, et al: Vascular endothelial growth factor in pleural effusions of different origin. Eur Respir J 25: 600-604, 2005.

18. Ruiz E, Alemán C, Alegre J, et al: Angiogenic factors and angiogenesis inhibitors in exudative pleural effusions. Lung 183 : $185-195,2005$.

19. Ferrara $N$ and Davis-Smyth T: The biology of vascular endothelial growth factor. Endocr Rev 18: 4-25, 1997.

20. Cheng D, Rodriguez RM, Perkett EA, et al: Vascular endothelial growth factor in pleural fluid. Chest 116: 760-765, 1999.

21. Grove CS and Lee YC: Vascular endothelial growth factor: the key mediator in pleural effusion formation. Curr Opin Pulm Med 8: 294-301, 2002.

22. Yancopoulos GD, Davis S, Gale NW, et al: Vascular-specific growth factors and blood vessel formation. Nature 407: 242-248, 2000.

23. Ferrara N, Carver-Moore $\mathrm{K}$, Chen $\mathrm{H}$, et al: Heterozygous embryonic lethality induced by targeted inactivation of the VEGF gene. Nature 380: 439-442, 1996.

24. Cheng D, Lee YC, Rogers JT, et al: Vascular endothelial growth factor level correlates with transforming growth factor-beta isoform levels in pleural effusions. Chest 118: 1747-1753, 2000.

25. Hamed EA, El-Noweihi AM, Mohamed AZ and Mahmoud A: Vasoactive mediators (VEGF and TNF-alpha) in patients with malignant and tuberculous pleural effusions. Respirology 9: 81-86, 2004.

26. Momi H, Matsuyama W, Inoue K, et al: Vascular endothelial growth factor and proinflammatory cytokines in pleural effusions. Respir Med 96: 817-822, 2002.

27. Kalomenidis I, Kollintza A, Sigala I, et al: Angiopoietin-2 levels are elevated in exudative pleural effusions. Chest 129: 1259-1266, 2006

28. Economidou F, Antoniou KM, Tzanakis N, et al: Angiogenic molecule Tie-2 and VEGF in the pathogenesis of pleural effusions. Respir Med 102: 774-779, 2008.

29. Duysinx BC, Corhay JL, Hubin L, et al: Diagnostic value of interleukin-6, transforming growth factor-beta 1 and vascular endothelial growth factor in malignant pleural effusions. Respir Med 102: 1708-1714, 2008.
30. Carlomagno F, Vitagliano D, Guida T, et al: ZD6474, an orally available inhibitor of KDR tyrosine kinase activity, efficiently blocks oncogenic RET kinases. Cancer Res 62: 7284-7290, 2002.

31. Ciardiello F, Bianco R, Caputo R, et al: Antitumor activity of ZD6474, a vascular endothelial growth factor receptor tyrosine kinase inhibitor, in human cancer cells with acquired resistance to antiepidermal growth factor receptor therapy. Clin Cancer Res 10: 784-793, 2004.

32. Frederick B, Gustafson D, Bianco C, et al: ZD6474, an inhibitor of VEGFR and EGFR tyrosine kinase activity in combination with radiotherapy. Int J Radiat Oncol Biol Phys 64: 33-37, 2006.

33. Hennequin LF, Stokes ES, Thomas AP, et al: Novel 4-anilinoquinazolines with $\mathrm{C}-7$ basic side chains: design and structure activity relationship of a series of potent, orally active, VEGF receptor tyrosine kinase inhibitors. J Med Chem 45: 1300-1312, 2002.

34. Wedge SR, Ogilvie DJ, Dukes M, et al: ZD6474 inhibits vascular endothelial growth factor signaling, angiogenesis and tumor growth following oral administration. Cancer Res 62: 4645-4655, 2002.

35. Williams KJ, Telfer BA, Brave S, et al: ZD6474, a potent inhibitor of vascular endothelial growth factor signaling, combined with radiotherapy: schedule-dependent enhancement of antitumor activity. Clin Cancer Res 10: 8587-8593, 2004.

36. Matsumori Y, Yano S, Goto H, et al: ZD6474, an inhibitor of vascular endothelial growth factor receptor tyrosine kinase, inhibits growth of experimental lung metastasis and production of malignant pleural effusions in a non-small cell lung cancer model. Oncol Res 16: 15-26, 2006.

37. Shibuya K, Komaki R, Shintani T, et al: Targeted therapy against VEGFR and EGFR with ZD6474 enhances the therapeutic efficacy of irradiation in an orthotopic model of human non-small cell lung cancer. Int J Radiat Oncol Biol Phys 69: 1534-1543, 2007.

38. Yano S, Herbst RS, Shinohara H, et al: Treatment for malignant pleural effusion of human lung adenocarcinoma by inhibition of vascular endothelial growth factor receptor tyrosine kinase phosphorylation. Clin Cancer Res 6: 957-965, 2000.

39. Wood JM, Bold G, Buchdunger E, et al: PTK 787/ZK 222584, a novel and potent inhibitor of vascular endothelial growth factor receptor tyrosine kinases, impairs vascular endothelial growth factor-induced responses and tumor growth after oral administration. Cancer Res 60: 2178-2189, 2000.

40. Li Q, Yano S, Ogino H, et al: The therapeutic efficacy of antivascular endothelial growth factor antibody, bevacizumab and pemetrexed against orthotopically implanted human pleural mesothelioma cells in severe combined immunodeficient mice. Clin Cancer Res 13: 5918-5925, 2007.

41. Thirkettle I, Harvey P, Hasleton PS, et al: Immunoreactivity for cadherins, $\mathrm{HGF} / \mathrm{SF}$, met and erbB-2 in pleural malignant mesotheliomas. Histopathology 36: 522-528, 2000.

42. Strizzi L, Catalano A, Vianale G, et al: Vascular endothelial growth factor is an autocrine growth factor in human malignant mesothelioma. Am J Pathol 193: 468-475, 2001.

43. Dazzi H, Hasleton PS, Thatcher N, et al: Malignant pleural mesothelioma and epidermal growth factor receptor (EGF-R). Relationship of EGF-R with histology and survival using fixed paraffin embedded tissue and the F4 monoclonal antibody. Br J Cancer 61: 924-926, 1990.

44. Thaker PH, Deavers M, Celestino J, et al: EphA2 expression is associated with aggressive features in ovarian carcinoma. Clin Cancer Res 10: 5145-5150, 2004.

45. Kinch MS, Moore MB and Harpole DH Jr: Predictive value of the EphA2 receptor tyrosine kinase in lung cancer recurrence and survival. Clin Cancer Res 9: 613-618, 2003.

46. Easty DJ, Herlyn M and Bennett DC: Abnormal protein tyrosine kinase gene expression during melanoma progression and metastasis. Int J Cancer 60: 129-136, 1995.

47. Xu F, Zhong W, Li J, et al: Predictive value of EphA2 and EphrinA-1 expression in oesophageal squamous cell carcinoma. Anticancer Res 25: 2943-2950, 2005.

48. Nasreen N, Mohammed KA and Antony VB: Silencing the receptor EphA2 suppresses the growth and haptotaxis of malignant mesothelioma cells. Cancer 107: 2425-2435, 2006.

49. Nasreen N, Mohammed KA, Lai Y and Antony VB: Receptor EphA2 activation with ephrin A1 suppresses growth of malignant mesothelioma (MM). Cancer Lett 258: 215-222, 2007.

50. O'Reilly MS, Boehm T, Shing Y, et al: Endostatin: an endogenous inhibitor of angiogenesis and tumor growth. Cell 88: 277-285, 1997. 
51. Nasreen N, Mohammed KA, Sanders K, et al: Pleural mesothelial cell (PMC) defense mechanisms against malignancy. Oncol Res 14: 155-161, 2003.

52. Nasreen N, Mohammed KA, Brown S, et al: Talc mediates angiostasis in malignant pleural effusions via endostatin induction. Eur Respir J 29: 761-769, 2007.

53. Bourguignon LY, Lokeshwar VB, Chen X and Kerrick WG: Hyaluronic acid-induced lymphocyte signal transduction and HA receptor (GP85/CD44)-cytoskeleton interaction. J Immunol 151: 6634-6644, 1993.

54. Nasreen N, Mohammed KA, Hardwick J, et al: Low molecular weight hyaluronan induces malignant mesothelioma cell (MMC) proliferation and haptotaxis: role of CD44 receptor in MMC proliferation and haptotaxis. Oncol Res 13: 71-78, 2002.

55. Tsigos S, Koutsilieris M and Papapetropoulos A: Angiopoietins in angiogenesis and beyond. Expert Opin Investig Drugs 12: 933-941, 2003

56. Thurston G, Rudge JS, Ioffe E, et al: Angiopoietin-1 protects the adult vasculature against plasma leakage. Nat Med 6: 460-463, 2006.

57. Thurston G, Suri C, Smith K, et al: Leakage-resistant blood vessels in mice trangenically overexpressing angiopoietin-1. Science 286: 2511-2514, 1999.

58. Kim I, Moon SO, Park SK, et al: Angiopoietin-1 reduces VEGFstimulated leukocyte adhesion to endothelial cells by reducing ICAM-1, VCAM-1 and E-selectin expression. Circ Res 89: 477-479, 2001.

59. Gamble JR, Drew J, Trezise L, et al: Angiopoietin-1 is an antipermeability and anti-inflammatory agent in vitro and targets cell junctions. Cir Res 87: 603-607, 2000.

60. Pizurki L, Zhou Z, Glynos K, et al: Angiopoietin-1 inhibits endothelial permeability, neutrophil adherence and IL-8 production. J Pharmacol 139: 329-336, 2003.

61. Maisonpierre PC, Suri C, Jones PF, et al: Angiopoietin-2, a natural antagonist for Tie 2 that disrupts in vivo angiogenesis. Science 277: 55-60, 1997.

62. Scharpfenecker M, Fiedler U, Reiss Y and Augustin HG: The Tie-2 ligand angiopoietin-2 destabilizes quiescent endothelium through an internal autocrine loop mechanism. J Cell Sci 118: 771-780, 2005.
63. Roviezzo F, Tsigkos S, Kotanidou A, et al: Angiopoietin-2 causes inflammation in vivo by promoting vascular leakage. J Pharmacol Exp Ther 314: 738-744, 2005.

64. Tanaka F, Yanagihara K, Otake Y, et al: Prognostic factors in resected pathologic (p-) stage IIIA-N2, non small cell lung cancer. Ann Surg Oncol 11: 612-618, 2004.

65. Tomimoto H, Yano S, Muguruma H, et al: Levels of soluble vascular endothelial growth factor receptor 1 are elevated in the exudative pleural effusions. J Med Invest 54: 146-153, 2007.

66. Aiuti A, Tavian M, Cipponi A, et al: Expression of CXCR4, the receptor for stromal cell-derived factor-1 on fetal and adult human lympho-hematopoietic progenitors. Eur J Immunol 29: 1823-1831, 1999.

67. Feng Y, Broder CC, Kennedy PE and Berger EA: HIV-1 entry cofactor: functional cDNA cloning of a seven transmembrane $G$, protein-coupled receptor. Science 1272: 872-877, 1996.

68. Strieter RM, Belperio JA, Phillips RJ and Keane MP: CXC chemokines in angiogenesis of cancer. Semin Cancer Biol 14: 195-200, 2004.

69. Phillips RJ, Burdick MD, Lutz M, et al: The stromal derived factor-1/CXCL12-CXC chemokine receptor 4 biological axis in non-small cell lung cancer metastases. Am J Respir Crit Care Med 167: 1676-1686, 2003.

70. Lee BC, Lee TH, Avraham S and Avraham HK: Involvement of the chemokine receptor CXCR4 and its ligand stromal cellderived factor 1alpha in breast cancer cell migration through human brain microvascular endothelial cells. Mol Cancer Res 2: 327-338, 2004.

71. Economidou F, Antoniou KM, Proklou A, et al: Investigation of angiogenetic mechanisms in pleural fluid of patients with lung cancer: preliminary results. Am J Respir Cell Mol Biol 179: A2876, 2009.

72. Kucia M, Jankowski K, Reca R, et al: CXCR4-SDF-1 signalling, locomotion, chemotaxis and adhesion. J Mol Histol 35: 233-245, 2004.

73. Oonakahara K, Matsuyama W, Higashimoto I, et al: Stromalderived factor $1 \alpha /$ CXCL12-CXCR4 axis is involved in the dissemination of NSCLC cells into pleural space. Am J Respir Cell Mol Biol 30: 671-677, 2004. 